\title{
Effectiveness of Educational Program Based on PRECEDE Model on Improving Sexual Function among Diabetic Women
}

\author{
Nevin Samir ${ }^{1}$, Randa Mohmed ${ }^{1}$, Dalia Ali Ameen ${ }^{2}$, Ahmed husseiny $^{3}$ \\ ${ }^{1}$ Assistant Prof. of Maternal and gynecological Nursing Department, Faculty of Nursing Ain Shams University \\ ${ }^{2}$ lecturer of medical surgical Nursing Department Ain Shams University \\ ${ }^{3}$ Assistant Prof. of obstetric and gynecological Department, Faculty of medicine, Ain Shams University, Cairo, \\ Egypt.
}

\begin{abstract}
A quasi-experimental study aimed to study the effect of an educational program based on the PRECEDE model on improving sexual function among diabetic women. Study was conducted at diabetic outpatient clinic at Ain shams university hospital. A convenience sampling technique was used to recruit one hundred seventy six (176) women with type II diabetes those were randomly divided into two equal groups. Data collected through three tools: $1^{\text {st }}$ tool PRECEDE model questionnaire, $2^{\text {nd }}$ tool Female Sexual Function Index and $3^{\text {rd }}$ tool ENRICH Marital Satisfaction Scale. Results: the study showed no statistical significant difference between control and intervention group regarding marital satisfaction and total score of female sexual function at base line assessment ( $p=0.317, p=0.945$ respectively). While, there was highly statistical significant difference between control and intervention group regarding marital satisfaction and total score of female sexual function after intervention ( $p=0.001, p=0.001$ respectively). Conclusion: The findings confirm the effectiveness of an educational program based on the PRECEDE model on improving sexual function among diabetic women. Recommendations: in the light of the previous results of the study the researchers recommended the following: application of educational program based on PRECEDE model for diabetic women in all available diabetic clinic or center to improve women's sexual function.
\end{abstract}

Keywords: PRECEDE model, diabetic women, Female Sexual Function Index, Marital satisfaction scale.

\section{Introduction}

Diabetes has been known as one of the major health challenges in developed and developing countries and imposes a large economic burden to patients, families, and healthcare systems although adequate control of glucose level in diabetes management is crucial to prevent complications. Diabetes mellitus is one of the most common chronic diseases in nearly all countries. In 2014, more than 387 million people had diabetes, and this is expected to rise to 592 million by 2035 , rendering previous estimates very conservative (1).

There are many risk factors for the developments of DM (diabetes mellitus) include sedentary lifestyle, obesity, and increased caloric consumption. Type 1 (T1DM; insulin dependent) and Type 2 (T2DM; noninsulindependent) DM can be major causes of system wide micro and macrovascular complications that ultimately impede the ability to sexually arouse males and females, so that they may be able to adequately perform sexual intercourse (2). Diabetes mellitus (DM) is a lifelong disease influencing lives of both the individual and his/her family in every aspect and decreasing quality of life due to obligatory lifestyle changes and various complications with a prevalence of $0.5-2 \%$ in a population (3). There are far fewer studies looking into the prevalence and the effect of diabetes on sexual function. In recent studies, the prevalence of FSD in diabetic women ranged between 27 to $75 \%$. This wide range might be due to the small number of subjects in each study and the subjective nature in determining the presence or absence of sexual dysfunction among diabetic women (4). Diabetes has the potential to affect sexual function in women through a variety of mechanisms, including vascular changes in the urogenital tissues affecting genital lubrication and neuropathy-mediated alterations in genital arousal response. Women's concern, satisfaction, and ability to participate in sexual activity may be influenced globally by the effect of diabetes on their overall health, physical and mental functioning, and interpersonal relationships. Additionally, sexual function may be adversely affected by diabetes medications or other health interventions directed at monitoring or treating this chronic disease (5).

Fundamental aspect of diabetes care is to provide skills and information that are required for best daily diabetes management and the main tool for maintaining metabolic control. Therefore, education is a costeffective element for effective disease management and provides the opportunity to avoid expensive medical treatment and co-morbid conditions. Several studies have shown that proper diabetes education has significant impact on decreasing diabetes complications. Although There are currently very few studies on the efficacy of the PRECEDE model in patients with DM2 (6). 
Health promotion program is the activities or strategies that are directed toward raising the general level of health and well-being of an individual. Activities include lifestyle modification: diet, exercise, weight control, sleep, stress management and other primary prevention strategies as smoking cessation and drug use (6)..Individual health education is considered to be essential in the overall care of patients with DM2, The PRECEDE (Predisposing, Reinforcing, Enabling, Causes in Educational Diagnosis, and Evaluation) model developed by (7) is one of the different educational models that focus on factors influencing health-related behavior, based on the relationship between the health professional and the patient, it is particularly appropriate for application in chronic diseases.

The PRECEDE model is a planning model for health promotion programs and provides a frame work where by predisposing factors (knowledge, attitudes, and beliefs), reinforcing factors (influence of others, family, peers, and health professionals), and enabling factors (availability of resources and skills) are determined as the factors that are most likely to affect behavior. The model shows how social, epidemiologic, and behavioral diagnosis results in a clear understanding of the needs, problems, and aspirations of people. It also evaluates the causes of behavioral factors that are closely related to health (8).

There were over 7.8 million cases of diabetes in Egypt in 2015. The rate of diabetes in Egypt has significantly increased exceeding international rates, according to the participants in the 4th Arab Diabetes forum. Egypt is now ranked eighth highest in the world in terms of the disease. In Egypt, the prevalence of diabetes is around $15.56 \%$ among adults between 20 and 79 years of age, with an annual death of 86,478 related to diabetes. (9).

Nurses play a key role in promoting health and wellness. Through health promotion and risk reduction, the individual develops behavior patterns that promote a healthy lifestyle and reduce the risk of disease. The challenge for nurses is to find ways to motivate clients and families to develop health-promoting behaviors. When behaviors that once worked for the individual are no longer effective, the client must give up the old behaviors to be able to adopt new. Client teaching is a major intervention for promoting health .So the nursing role should develop and encourage a comprehensive and realistic lifestyle educational program with simple methods to facilitate implementation on a large scale. Many strategies and guidelines for standard of care are still needed to adopt the sexual problems issues among diabetic women. Nursing education is an important aspect of self-management in diabetes helps the diabetic woman feel better. Nursing intervention was effective to provide awareness regarding knowledge of sexual dysfunction among patients with diabetes. (10)

\section{Justification of the study:}

Sexual dysfunction is prevalent in patients with type 2 diabetes mellitus, but remains one of the most frequently neglected complications in diabetes care. So the nurse plays an important role in prevention and health promotion activities for diabetic women with Sexual dysfunction, despite that both patients and care providers appear to have difficulty with discussing sexual problems during diabetes care. The studies suggested that, sexual educational program based on PRECEDE model, might be a useful tool to improve the discussion of sexual issues for nurses and patients with type 2 diabetes mellitus.

\section{Aim of the study:}

The present study was conducted to evaluate the effectiveness of an educational program based on the PRECEDE model on improving sexual function among diabetic women.

\section{Research Hypothesis:}

Sexual function of diabetic women who received educational program based on PRECEDE model will be improved more than diabetic women who received routine care.

\section{Subject \& methods}

Research design: A quasi-experimental study design was used.

Setting: The study was conducted at outpatient diabetic clinic at Ain shams University Hospital.

Sample size, type, and technique:

The required sample size was one hundred and eighty four women based on the following equation $\mathrm{n}=\frac{\mathrm{t}^{2} \times \mathrm{p}(1-\mathrm{p})}{\mathrm{m}^{2}}$

$\mathrm{n}=$ required sample size

$\mathrm{t}=$ confidence level at $95 \%$ (standard value of 1.96 )

$\mathrm{p}=$ estimated prevalence of sexual problem among diabetic women.

$\mathrm{m}=$ margin of error at $5 \%$ (standard value of 0.05 )

A purposive sample technique was used to recruit one hundred and eighty four(184) women in the study. Thesis women were randomly divided to two groups control and intervention. Based on the following criteria; 
educated women with type 2 diabetes mellitus, aged $20-48$ years (reproductive age), who indicate to be dissatisfied about their sexual functioning and that they would like to talk about their sexual problem(s). Diabetic women were excluded from participation if they had any other medical diseases. Sexually inactive women in last four week were not included. This sample size reached to one hundred seventy six(176) women as eight $(8)$ women were lost at the time of the follow up as for a cultural issues and shame.

\section{Tools of data collection:}

I. Interviewing questioner: (a) Assess the patient socio-demographic characteristics (b) Assess the patient diabetes history (past and present)

II. The questionnaire related to the PRECEDE model frame work was specifically developed for the current study on the basis of points raised in group discussions and in relevant books and articles. The questionnaire evaluated 20 items in three domains: predisposing factors (13 items), enabling factors (4 items), and reinforcing factors ( 3 items). In the domain of predisposing factors, knowledge ( 6 items) was evaluated on the basis of yes/no/don't know questions (possible score 6-18), and attitudes, beliefs, and values (7 items) were evaluated using a three-point Likert scale (from agree $=3$, uncertain $=2$, and disagree $=1$, possible score (7-21). The researcher considers negative attitude if total score was less than 14 while, positive attitude, if the total score more than 14 . The quantitative face validity and the qualitative content validity of the questionnaire were assessed through jury consist of 5 expert faculty members in obstetric and gynecological and medical surgical nursing field. Additionally, (18) women who had diabetes were asked to review the questionnaire. These patients and the expert panel mostly indicated that the questionnairewas easy to read and understand.The reliability was evaluated on the basis of the test-retest method, the correlation coefficients (r) obtained from the test-retest evaluations were 0.90 .

III. The Female Sexual Function Index "FSFI" was developed and validated by (11) to measures sexual function. It consistsof 19-item questionnaire that is subdivided into six domains in six domains: desire, arousal, lubrication, orgasm, satisfaction, and pain. Each domain is rated on a scale of 0-6, full scale range from 2 -36 with higher scores indicatingbetter sexual function. Overall test-retest reliability coefficients were cronbach's alpha values of 0.82 .

IV. ENRICH Marital Satisfaction Scale was developed and validated by (12) EMS Scale is a 15-item scale comprising the Idealistic Distortion (5 items) and Marital Satisfaction Scale (10 items). Each of the 10 marital satisfaction items represents one of the areas of the marital relationship which includes personality issues, communication, conflict resolution, financial management, leisure activities, sexual relationship, children and parenting, family and friends, equalitarian roles and religious orientation. It is on a 5 point Likert scale. The highest score for the EMS is 75 and the lowest is 15. The higher the score, the more satisfaction with sexual life. Cronbach's alpha revealed an internal reliability of 0.86 .

All participants receive an Arabic booklet as supportive material for program. In the intervention group, each participant will also receive educational program based on the PRECEDE model.

\section{Pilot Study}

It was conducted on $10 \%$ of the study sample eighteen (18) diabetic women, were selected randomly and excluded from the main study sample. Its aim was to evaluate the simplicity and clarity of the tools. It also helped in the estimation of the time needed to fill in the forms. According to the results of the pilot study, simple modifications were done as rephrasing questions or cancelling some questions.

\section{Ethical consideration}

The approval was obtained from Scientific Research Ethical committee in Faculty of Nursing at Ain Shams University before starting the study. Then an official permission was granted from the director of the Ain Shams University Hospital. The researchers introduced themselves to the women who met the inclusion criteria and informed them about the purpose of this study in order to obtain their acceptance to share in this study. The researchers ensured that, the study posed no risk or hazards on their health and their participation in the study is voluntary. Women who were willing to participate in the study and met the inclusion criteria were approached by the researchers and asked for verbal consent to confirm their acceptance, and all events that occurred during data collection were considered confidential. 


\section{Study Procedures}

Researchers collected data four days per week from 9 am to $2 \mathrm{pm}$. data collection started at the beginning of March 2015 to the end of March 2016. After women had been fully informed about the research and consented for participation in the research. Data collection procedure has been done through three phases; interviewing and assessment, implementation and evaluation phase.

Assessment phase: done at diabetic clinic where researchers met each participant individually and fill tools of data collection at first meeting.

\section{Implementation phase: Intervention group:}

The PRECEDE model is a diagnostic tool behavior and therefore the first step in its implementation is to identify the behavior to be analyzed. The model considers the influence of the following three factors on health-related behavior firstly Predisposing factors influencing the patient's motivation to undertake the behavior to be analyzed or encouraged, then facilitators factors influencing the level of easiness or difficulty the patient and his/her family have in undertaking a given behavior and finally reinforcing factors' arising after the patient has undertaken the behavior, and which reward or punish it. The program was conducted in diabetic clinic at Ain Shams University Hospital. The participated women received four session based on PRECEDE model. The researchers established the session's environment to be comfortable and quiet. The researchers used a well prepared intervention materials and contents in the form of comprehensive illustrated booklet related to the selected nursing management. A four sessions each session lasting 30-40 minute, with one session conducted per week. The researchers offered information to the patient about effect of diabetes on sexual function, sexual problems, sexual attitudes, and practices to improve sexual function. In first and second sessions researchers first looked at predisposing factors that influence the analyzed behavior. Patient's responses and comments were written in two parallel lists: positive (+) and negative (-) factors in patients behaviors that need improvement. Predisposing factors are subjective (beliefs, opinions, values, thoughts, knowledge). Subsequently, factors that facilitate the studied behavior were analyzed. These are objective factors such as patient's skills or availability of resources. For example if a women expressed anticipatory anxiety about sexual intercourse with her husband for fear of pain or discomfort, the researchers addressed multiple examples of 'specific suggestions' will be given, such as prescribing lubricants or phosphodiesterase-5 inhibitors (under doctor prescription). While, third and fourth sessions the researchers discussed the following question with the intervention group: What does the patient need to change behavior? "Through knowledge, training program / counseling (increasing time of fore play, change position of sexual relation, practice exercise regularly "kegel ex", personal hygiene and diabetes control). After, two behaviors were selected for each woman. Finally, subjective Reinforcing factors (what the woman says after her behavior and objectives (response to social and family environment, physical, emotional, and economic consequences).

\section{Control group:}

Women in the control group received only routine care which covered diabetic care without sexual education. The data collected during the study comprised demographic data and information about sexual function, knowledge and attitudes.

\section{Evaluation phase:}

Both groups (control and intervention) were interviewed after the intervention by 4 weeks \& 8 weeks for filling the Female Sexual Function Index (FSFI), and ENRICH Marital Satisfaction scale. While a questionnaire based on the PRECEDE framework was fill twice before and after intervention by 8 weeks. Interviews were conducted at the out -patient diabetes clinic by researchers at the same time of patient's follow up routinely every month.

\section{Statistical analysis:}

The data were analyzed using SPSS version 18.0. The $t$ and $\chi 2$ tests were employed to compare quantitative and qualitative demographic variables between the groups, respectively. The ANOVA test was used for withingroup comparisons and between groups' comparisons of knowledge, attitudes, and sexual function.

\section{Results}

Table (1): indicates that $54.5 \%$ of women in control were in age between 30-39 years old compared to $53.4 \%$ of women in the study group. As regard educational level, $25.0 \%$ of women in control group had university education versus $29.5 \%$ in intervention group. Concerning occupation, $71.6 \%$ of women in control group were working for cash compared to $68.2 \%$ in intervention group. As regard place of residence, $77.3 \%$ of women in control group were from urban area compared to $68.2 \%$ in intervention group. Moreover, $28.4 \%$ of women in control group were married for more than t 10 years compared to $33 \%$ of women in the study group. In addition there was no statistical significant difference between control and study group regarding their personal characteristics. 
Table (2): shows that $42.0 \%$ of women in control group had diabetes as a chronic disease for more than 10 years compared to $43.2 \%$ of women in the intervention group. Concerning glucose control $51.1 \%$ of women in control group had glucose control versus $47.7 \%$ of women in the intervention group. As regard diabetic complications $10.2 \%$ of women in the control group had diabetic complication compared to $11.4 \%$ of women in the intervention group. Concerning type of diabetic complications $66.7 \%$ of women in control group had peripheral neuropathy complications versus $70.0 \%$ of women in the intervention group.

Table (3): reveals that there was no statistical significant difference between control and intervention group regarding enrich marital satisfaction scale, subtotal and total score of female sexual function at base line assessment.

Table (4): shows that there was highly statistical significant difference between control and intervention group regarding enrich marital satisfaction scale, and total score of female sexual function after intervention. Moreover, there highly significant difference between control and intervention group regarding subtotal domains of FSF (desire and satisfaction) and significant difference between control and intervention group regarding other subtotal domains expect lubrication.

Table (5): reveals that there was a highly statistical significant improvement on total score of FSF and enrich marital satisfaction scale after application of program in the intervention group. Meanwhile the improvement of total score of FSF and enrich marital satisfaction scale in the control group was not significant.

Table (6) indicates that the highly statistically significant independent predictor of women' FSF score were age, educational level, occupation, residence, duration of diabetes, glucose control and absent of diabetic complication were [positive predicator $\beta=0.421,0.045,0.370,0.050,0.238,0.178$ and 0.209 ] respectively. The model explains $82.1 \%$ of the variations in women's FSF score, as indicated by the value of r-square.

Table (1): Comparison between control and intervention groups regarding their personnel characteristics.

\begin{tabular}{|c|c|c|c|c|c|c|}
\hline \multirow{2}{*}{ Personnel characteristics } & \multicolumn{2}{|c|}{$\begin{array}{c}\begin{array}{c}\text { Control group } \\
n=88\end{array} \\
\end{array}$} & \multicolumn{2}{|c|}{$\begin{array}{c}\begin{array}{c}\text { Intervention group } \\
\mathrm{n}=\mathbf{8 8}\end{array} \\
\end{array}$} & \multirow[t]{2}{*}{$\mathbf{X}^{2}$} & \multirow[t]{2}{*}{$P$ value } \\
\hline & No & $\%$ & No & $\%$ & & \\
\hline \multicolumn{5}{|l|}{ Age } & \multirow{5}{*}{1.97} & \multirow{5}{*}{0.072} \\
\hline $20-$ & 18 & 20.5 & 20 & 22.7 & & \\
\hline $30-$ & 48 & 54.5 & 47 & 53.4 & & \\
\hline $40-48$ & 22 & 25.0 & 21 & 23.9 & & \\
\hline Mean \pm SD & \multicolumn{2}{|c|}{$35.56 \pm 6.83$} & \multicolumn{2}{|c|}{$34.56 \pm 7.05$} & & \\
\hline \multicolumn{5}{|l|}{ Educational qualification } & \multirow{4}{*}{2.23} & \multirow{4}{*}{0.060} \\
\hline Primary & 15 & 17.0 & 16 & 18.2 & & \\
\hline Secondary & 51 & 58.0 & 46 & 52.3 & & \\
\hline University & 22 & 25.0 & 26 & 29.5 & & \\
\hline \multicolumn{5}{|l|}{ Occupation } & \multirow{3}{*}{0.691} & \multirow{3}{*}{0.097} \\
\hline House wife & 25 & 28.4 & 28 & 31.8 & & \\
\hline Working & 63 & 71.6 & 60 & 68.2 & & \\
\hline \multicolumn{5}{|l|}{ Residence } & \multirow{3}{*}{1.59} & \multirow{3}{*}{0.087} \\
\hline Urban & 68 & 77.3 & 64 & 72.7 & & \\
\hline Rural & 20 & 22.7 & 24 & 27.3 & & \\
\hline \multicolumn{5}{|l|}{ Duration of marriage } & \multirow{4}{*}{2.01} & \multirow{4}{*}{0.061} \\
\hline$>5$ years & 12 & 13.6 & 11 & 12.5 & & \\
\hline $5-10$ years & 51 & 58.0 & 48 & 54.5 & & \\
\hline$<10$ years & 25 & 28.4 & 29 & 33.0 & & \\
\hline
\end{tabular}

Table (2): Comparison between both group "control and intervention" as regard history of diabetes.

\begin{tabular}{|c|c|c|c|c|c|c|}
\hline \multirow[t]{2}{*}{ Items } & \multicolumn{2}{|c|}{$\begin{array}{c}\text { Control group } \\
n=88\end{array}$} & \multicolumn{2}{|c|}{$\begin{array}{c}\begin{array}{c}\text { Intervention group } \\
\mathrm{n}=88\end{array} \\
\end{array}$} & \multirow[t]{2}{*}{$\mathbf{X}^{2}$} & \multirow[t]{2}{*}{$P$ value } \\
\hline & No & $\%$ & No & $\%$ & & \\
\hline \multicolumn{5}{|l|}{ Duration of Diabetes } & \multirow{4}{*}{1.23} & \multirow{4}{*}{0.097} \\
\hline$>5$ years & 22 & 25.0 & 20 & 22.7 & & \\
\hline $5-10$ years & 29 & 33.0 & 30 & 34.1 & & \\
\hline$<10$ years & 37 & 42.0 & 38 & 43.2 & & \\
\hline \multicolumn{5}{|l|}{ Glucose control } & \multirow{3}{*}{1.65} & \multirow{3}{*}{0.082} \\
\hline Yes & 45 & 51.1 & 42 & 47.7 & & \\
\hline No & 43 & 48.9 & 46 & 52.3 & & \\
\hline \multicolumn{5}{|l|}{ Diabetic complications } & \multirow{3}{*}{1.09} & \multirow{3}{*}{0.075} \\
\hline Yes & 9 & 10.2 & 10 & 11.4 & & \\
\hline No & 79 & 89.8 & 78 & 88.6 & & \\
\hline \multicolumn{5}{|c|}{ Types of Diabetic complications } & \multirow{3}{*}{2.03} & \multirow{3}{*}{0.064} \\
\hline Peripheral neuropathy & 6 & 66.7 & 7 & 70.0 & & \\
\hline Renal complication & 3 & 33.3 & 3 & 30.0 & & \\
\hline
\end{tabular}


Effectiveness of Educational Program Based on PRECEDE Model on Improving Sexual Function ..

Table (3): Distribution of the studied women according to FSF scores and EMS scale at baseline.

\begin{tabular}{|l|c|c|c|c|}
\hline \multicolumn{1}{|c|}{ Items } & $\begin{array}{c}\text { Control group } \\
\mathbf{n = 8 8}\end{array}$ & $\begin{array}{c}\text { Intervention group } \\
\mathbf{n = 8 8}\end{array}$ & Independent T test & P Value \\
\hline Desire & $4.65 \pm 1.61$ & $4.62 \pm 1.61$ & 2.13 & 0.654 \\
\hline Arousal & $2.86 \pm 1.31$ & $2.62 \pm 1.01$ & 1.58 & 0.319 \\
\hline Lubrication & $3.32 \pm 1.41$ & $3.00 \pm 1.26$ & 1.06 & 0.109 \\
\hline Orgasm & $3.23 \pm 1.37$ & $2.98 \pm 1.30$ & 1.94 & 0.297 \\
\hline Satisfaction & $3.16 \pm 1.32$ & $3.18 \pm 1.13$ & 2.61 & 0.958 \\
\hline Pain & $3.58 \pm 1.50$ & $3.28 \pm 1.55$ & 1.75 & 0.182 \\
\hline Total FSF score & $20.82 \pm 7.77$ & $19.70 \pm 6.72$ & 1.32 & 0.317 \\
\hline Total EMS & $46.52 \pm 2.76$ & $47.02 \pm 2.16$ & 0.369 & 0.945 \\
\hline
\end{tabular}

FSF "female sexual function"

EMS "enrich marital satisfaction"

Table (4): Distribution of the studied women according to female sexual function scores and EMS after intervention by 8 weeks.

\begin{tabular}{|l|c|c|c|c|}
\hline \multicolumn{1}{|c|}{ Items } & $\begin{array}{c}\text { Control group } \\
\mathbf{n = 8 8}\end{array}$ & $\begin{array}{c}\text { Intervention group } \\
\mathbf{n = 8 8}\end{array}$ & Independent T test & P Value \\
\hline Desire & $9.02 \pm 3.42$ & $13.30 \pm 1.89$ & 8.43 & $0.001^{* *}$ \\
\hline Arousal & $2.87 \pm 1.30$ & $4.28 \pm 0.65$ & 6.58 & $0.03^{*}$ \\
\hline Lubrication & $3.28 \pm 1.43$ & $4.65 \pm 0.49$ & 3.76 & 0.06 \\
\hline Orgasm & $3.20 \pm 1.38$ & $4.88 \pm 0.63$ & 5.94 & $0.04^{*}$ \\
\hline Satisfaction & $3.26 \pm 1.18$ & $134.91 \pm 0.70$ & 12.53 & $0.001^{* *}$ \\
\hline Pain & $3.51 \pm 1.39$ & $4.61 \pm 0.50$ & 6.75 & $0.03^{*}$ \\
\hline Total FSF score & $25.01 \pm 9.22$ & $42.33 \pm 6.74$ & 9.32 & $0.001^{* *}$ \\
\hline Total EMS & $47.52 \pm 2.76$ & $68.81 \pm 4.66$ & 24.59 & $0.001^{* *}$ \\
\hline
\end{tabular}

Figure (1): Comparison between control and intervention groups according to their knowledge regarding sexual function for diabetic women before and after intervention.

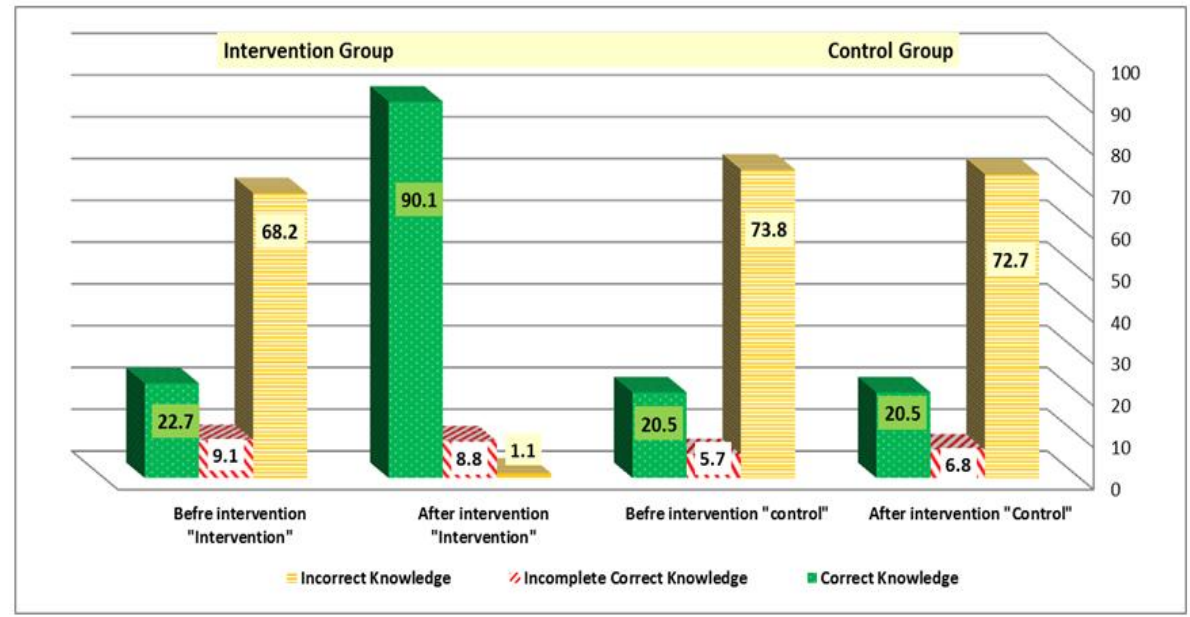

Figure (2): Comparison between control and intervention groups according to their attitude regarding sexual function before and after intervention.

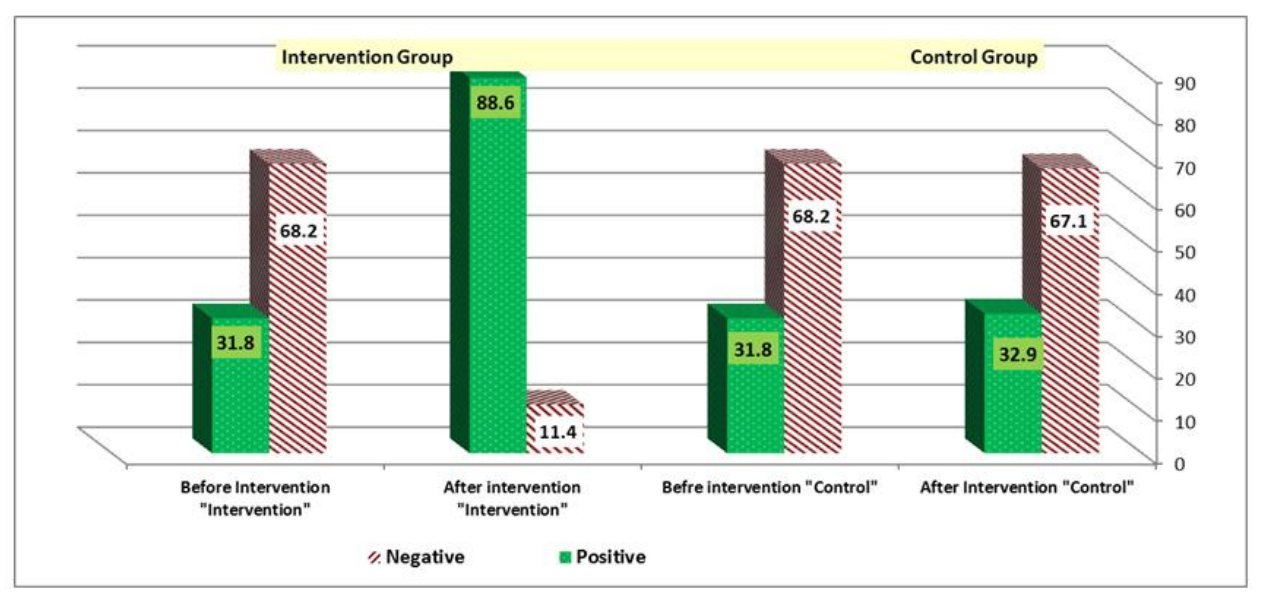


Effectiveness of Educational Program Based on PRECEDE Model on Improving Sexual Function ..

Table (5): Comparison of total Female Sexual Function Scores and EMS for studied groups.

\begin{tabular}{|l|c|c|c|c|c|}
\hline \multicolumn{1}{|c|}{ Items } & Baseline assessment & $\begin{array}{c}\text { 4 weeks } \\
\text { after intervention }\end{array}$ & $\begin{array}{c}\text { 8 weeks after } \\
\text { intervention }\end{array}$ & F test & P value \\
\hline Total FSF & & & & & \\
Intervention group & $19.70 \pm 6.72$ & $36.65 \pm 4.07$ & $42.33 \pm 6.74$ & 24.59 & 0.001 ** \\
Control group & $20.82 \pm 7.77$ & $25.17 \pm 9.57$ & $25.01 \pm 9.22$ & 2.832 & 0.076 \\
\hline Total EMS & & & & & \\
Intervention group & $47.02 \pm 2.16$ & $63.52 \pm 3.41$ & $68.81 \pm 4.66$ & 18.33 & $0.001 * *$ \\
Control group & $46.52 \pm 2.76$ & $47.67 \pm 2.51$ & $47.52 \pm 2.76$ & 2.832 & 0.076 \\
\hline
\end{tabular}

** Highly statistical significant.

Table (6): liner regression analysis for women's FSF score with their sociodemographic characteristics and disease history for intervention group

\begin{tabular}{|l|c|c|c|c|}
\hline \multicolumn{1}{|c|}{ Items } & Beta & t & Sig. & 95.0\% C I \\
\hline (Constant FSF after intervention) & 2.166 & 27.027 & .000 & 2.008 to 2.323 \\
\hline Age "20-30 years" & .421 & 4.766 & .000 & .247 to .594 \\
\hline Educational qualification " Primary " & .045 & 2.160 & .031 & .004 to .087 \\
\hline Occupation "House wife" & .370 & 5.395 & .001 & .235 to .505 \\
\hline Residence "Rural" & .050 & 1.985 & .048 & .000 to .099 \\
\hline Duration of marriage "<10 years" & .049 & 1.892 & .059 & -.002 to .100 \\
\hline Duration of Diabetes "> 5 years" & .238 & 3.476 & .001 & .103 to .372 \\
\hline Glucose control "Yes" & .178 & 3.057 & .002 & .064 to .292 \\
\hline Diabetic complications "No" & .209 & 3.190 & .002 & .080 to .337 \\
\hline
\end{tabular}

$\mathrm{r}=76.7, \mathrm{r}$ square $=82.1, \mathrm{~F}=\mathbf{1 0 . 2 3}, \mathrm{p}$ value $0.001 * *$

\section{Discussion}

Sexual problems of women with diabetes deserve more attention in clinical research and practice. There are currently very few studies on the efficacy of the PRECEDE model in patients with DM2. In Egypt the present study considered from the first studies which evaluated the effect of an educational program based on the PRECEDE model on women with DM2. Appropriate education is one of the basic points in the promotion of knowledge, attitude and practice. The results of this study showed that design and implementation of educational program in accordance with The PRECEDE model can create a significant difference in the rate of knowledge, attitude, enabling and reinforcing factors of patients before and after intervention and conducting effective self -care behaviors in women's sexual function.

The present study showed that the total size of sample was one hundred seventy six(176) diabetic women were varied between 20-48 years, the mean age of women with diabetes was $(35.56 \pm 6.83)$ and the higher percent of diseased women were had 30-40 years. These findings are came in line with (13) who mentioned that, middle and late adulthood populations are the major drivers of the increasing prevalence of diabetes in Egypt and Africa in general. While the current study results was not in the same line with (14) who stated that, people who develop diabetes are usually under the age of 20 . This came in line with the study results of (15) who emphasized that most people with diabetes in low and middle income countries are between 40 and 60 years old for both sexes. Regarding educational levels of the subjects, the current study results revealed that more than half of studied women were secondary educated. This finding agreement with(16) who stated that, the prevalence rates of diagnosed diabetes are significantly lower among adults with higher levels of educational attainment.

Regarding sexual function before intervention the result of the present study revealed that there was no statistical significant difference between control and intervention group regarding subtotal and total score of female sexual function at base line assessment. This relation was reversed to highly statistical significant difference between control and intervention group regarding enrich marital satisfaction scale, and total score of female sexual function after intervention with educational program based on PRECEDE model after 8 weeks. Moreover, there was a highly significant difference between control and intervention group regarding subtotal domains of FSF (desire and satisfaction) and significant difference between control and study group regarding other subtotal domains expect lubrication.

The current study findings was in the same line with the findings of (17) that showed significant relationship between DM control and sexual dysfunction and its affecting factors in women with DM. Sexual dysfunction rate was reported to change between $42-60 \%$ for women by studies implemented in a healthy society. Sexual function scores for the sexual drive, arousal, vaginal lubrication, orgasm and overall satisfaction domains were all lower in the diabetic women ( $\mathrm{p}$ value $<0.05)$.

Moreover the current study finding supported with (18) who conducted study to investigate the effectiveness of sexual health education on sexual function during pregnancy and reported that after sexual education, there were significant differences in sexual desire $(\mathrm{P}=0.003)$, sexual arousal $(\mathrm{P}=0.003)$, orgasm $(\mathrm{P}=0.007)$, and dysparunia $(\mathrm{P}<0.001)$ between two groups

\begin{tabular}{lll}
\hline DOI: $10.9790 / 1959-0602046169$ & www.iosrjournals.org & $67 \mid$ Page
\end{tabular}


This study findings were also supported by (19) who carried out semi-experimentally and a pretestpost-test designed control group to investigate the effectiveness of sexual education focused on cognitive schemas, on the improvement of sexual functioning of female married students and mentioned that there was significant relationship between the two groups in the overall scores of sexual functioning, sexual desire, arousal, moisture, orgasm and sexual satisfaction, in a way that in all cases the scores of the experimental group were significantly higher than those of the control group $(\mathrm{p}<0.001)$. However, $t$-test reported no significant difference between the two groups in terms of sexual pain component.

In addition, the result of the present study revealed that improvement on FSF total score was reflected upon improvement on enrich marital satisfaction scale after intervention in the study group. The present findings were agreed with (20) who develop a conceptual model that links married older adults physical health and that of their spouse to positive and negative dimensions of marital quality via psychological well-being of both partners and their sexual activity and reported that sexual activity mediates the association between own and partner's physical health and positive marital quality. This could be explained as sexual and marital satisfactions are equally tied together for men and women.

The current study findings were in the same with (21) study which revealed that sexual dysfunction was associated with lower overall quality of marital relation and DM; this is not surprising because the relation between marital relation, DM, and sexual dysfunction is well established in the literature .Moreover, the result of the current study indicates that the highly statistically significant independent predictor of women' FSF score were age, educational level, occupation, residence, duration of diabetes, glucose control and absent of diabetic complication were [positive predicator $\beta=0.421,0.045,0.370,0.050,0.238,0.178$ and 0.209 ] respectively. The present study finding was in the same line (22) who reported that age was negatively correlated with all domains of sexual function in women with type 2 DM conversely education, diabetic duration, diabetic control, and diabetic complication were not correlated to sexual dysfunction in diabetic women.

The current study considered one from a very few studies which studied the efficacy of the PRECEDE model on knowledge and attitude of women with DM regarding to sexual dysfunction issues, the current study has been proven the positive efficiency of the PRECEDE model, this revealed in figures 1 and 2 which illustrated the significant difference of intervention group regarding correct complete knowledge from 22.7 to 90.1 respectively before and after application of educational program based on PRECEDE model. Furthermore fig 2 illustrates big conversion from 31.8 to 88.6 third quarter of intervention group have a positive attitude regarding to their sexual function after application of program in comparison to control group who receive routine care the study clarify a slightly change from 31.8 to 32.9 only regarding positive attitude of control group regarding to their sexual function. The current study findings are matching with (23) study results who mentioned that the utilization of the PRECEDE (Predisposing, Reinforcing, Enabling, Causes in Educational Diagnosis, and Evaluation) education model in the metabolic control and the reduction of cardiovascular risk factors, in patients with type 2 diabetes it has a positive effect .

Finally, there was a significant improvement for the intervention group than in the control group in all domains of sexual function, it can be concluded that the combination of sexual education and sexual skills training along with attention to factors such as knowledge, attitudes, and requirements can affect sexual function, and this could be the reason for the effectiveness of the PRECEDE model. In addition, the results indicated that the PRECEDE behavioral model, which focuses on predisposing, reinforcing, and enabling factors, can improve sexual function in women with type II diabetes despite disorders in their sexual desire and function arisen from physiological problems

\section{Conclusion \& Recommendation}

Conclusion: the findings of the current study supported the hypothesis of this study which stated that Sexual function of diabetic women who received educational program based on PRECEDE model will be improved more than diabetic women who received routine care. Even in communities with model in terms of a high sensitivity toward sexual matters where cultural, religious and social influences make it difficult and sometimes impossible to provide sexuality-related training, the program can be designed according to local needs and desires.

Recommendations: in the light of the previous results of the present study the following recommendations are suggested; application of educational program based on PRECEDE model for diabetic women in all available diabetic clinics or centers to improve women's sexual function. Further researches is needed to compare effect of PRECEDE model versus other models as ALARM, BETTER, and PLISSIT models on improving sexual function among women with diabetes. 


\section{References}

[1] International Diabetes Federation. (2014): IDF Diabetes Atlas, 5th edition. Update. Brussels, Belgium: International Diabetes Federation.

[2] Jason Gandhi, GautamDagur, Kelly Warren, Noel Smith and Sardar Ali Khan., (2016): Effect of Diabetes Mellitus on Sexual Arousal and Intercourse. Transl Biomed.7:2.

[3] Zeliha Kaya Erten, Handan Zincir, Filiz€Ozkan, AlimeSelc_uk and FerhanElmal1., (2013):Sexual lives of women with diabetes mellitus (type 2) and impact of culture on solution for problems related to sexual life. Journal of Clinical Nursing, 23, 995-1004.

[4] Maria Ida Maiorino, Giuseppe Bellastella, and Katherine Esposito (2014): Diabetes and sexual dysfunction: current perspectives. Diabetes, Metabolic Syndrome and Obesity; 7: 95-105.

[5] Kelli L. Copeland, Jeanette S. Brown, Jennifer M. Creasman, Stephen K. Van Den Eeden, Leslee L. Subak, David H. Thom, Assiamira Ferrara, and Alison J. Huang. (2012): Diabetes Mellitus and Sexual Function in Middle-Aged and Older Women. Obstet Gynecol.120 (2) 331-340.

[6] Seyda Ozcan , Nevin Hotun Sahin , Dilek Bilgic ,Sema Dereli Yilmaz., (2011): Is Sexual Dysfunction Associated with Diabetes Control and Related Factors in Women with Diabetes? Sex Disabil: 29:251-261

[7] Green LW, Kreuter MW (2005): Health Program Planning: An Educational and Ecological Approach. 4th edition. New York: McGraw-Hill Higher Education; PP 208.

[8] Nazafarin Hosseini, Akram Amini, AliKaram Alamdari, Mohsen Shams, Mehrdad Vossoughi, Fatemeh Bazarganipour., (2016): Application of the PRECEDE model to improve sexual function among women with hysterectomy. International Journal of Gynecology and Obstetrics.Vol.132, 229-233.

[9] Shalaby Sherif and Bauer E Sumpio"( 2015) Economic development and diabetes prevalence in MENA countries: Egypt and Saudi Arabia comparison World J Diabetes. 2015 Mar 15; 6(2): 304-311.

[10] Indi S. A study to assess the effectiveness of structured teaching programme on knowledge regarding self care activities among patients with diabetes mellitus. In A Selected Phc at Tumkur. Iosr Journal of Nursing And Health Science (Iosr-Jnhs). 2015; 4(3):18. Available from: www.iosrjournals.org

[11] Rosen R, Brown C. et al. (2000) The Female Sexual Function Index (FSFI): a multidimensional self-report instrument for the assessment of female sexual function. J Sex Marital Ther; 26(2):191-208.

[12] Fower, B., and Olson, D.H.,(1993):ENRICH Marital Satisfaction Scale: A brief research and clinical tool. Journal of Family Psychology. 7 (2):176-185.

[13] Taghdisi MH, Borhani M, Solhi M, Afkari ME, Hosseini ME. (2011): Effect of educational program based on PRECED model on quality of life in patients with type II diabetes. J Gorgan Uni Med Sci. 13: 29-36.

[14] American Diabetes Association. (2009), Standards of Medical Care in Diabetes. January; 32 (Suppl 1): S13-S61. PMCID: PMC2613589 doi: 10.2337/dc09-S013

[15] Nuriye Buyukkayaci Duman., (2014): Frequency of sexual dysfunction and its causative factors among diabetic women in Turkey Pak J Med Sci; 30(3): 558-563.

[16] Connecticut DPH. (2013): Connecticut BRFSS, 2011 unpublished data. Connecticut DPH, Hartford, CT.revalence in Connecticut, 201

[17] Giraldi A., and Kristensen E. (2010): Sexual dysfunction in women with diabetes mellitus. J Sex Res. $47: 199$ - 211.

[18] Riazi Hedyeh, Banoo Zadeh Sahar, Moghim Beigi Abbas, Amini Leila (2013): The Effect of Sexual Health Education on Sexual Function During Pregnancy. PAYESH 12 (4): P 367 - 374.

[19] Ziaee, P., Sepehri Shamlou, Z., Mashhadi, A. (2014): The effectiveness of sexual education focused on cognitive schemas, on the improvement of sexual functioning among female married students. J Evid Based Care. 4 (11): P 73-82

[20] Adena M. Galinsky and Linda J. Waite (2013): Sexual Activity and Psychological Health As Mediators of the Relationship Between Physical Health and Marital Quality. Journals of Gerontology, Series B: Psychological Sciences and Social Sciences

[21] Farideh Nabizadeh, and Abed Mahdavi (2016): Relationship between Hardiness and Marital Satisfaction in Women with Breast Cancer. Arch Breast Cancer Vol. 3, No. 3: 92-96.

[22] Forouyan Elyasi, Zahra Kashi, Bentolhoda Tasfieeh, Adele Bahar, and Mohammed Khademloo. (2015): Sexual dysfunction in women with type 2 diabetes mellitus. Iran J Med Sci. 40 (3): 206 - 213.

[23] Shamsi M, Sharifi Rad GH, Kachoei A, Hasan Zadeh A, Dejham S. (2010): The effect of educational program based on health belief model on control sugar in woman by type 2 diabetics. IJEM; 11: 490-99. 